\section{RMD Open}

Rheumatic \&

Musculoskeletal Diseases

\title{
Passive smoking in childhood and adulthood and risk of rheumatoid arthritis in women: results from the French E3N cohort study
}

\author{
Yann Nguyen (D) , , ${ }^{1,2}$ Carine Salliot, ${ }^{1,3}$ Amandine Gelot, ${ }^{1}$ Xavier Mariette (i) , 4,5 \\ Marie-Christine Boutron-Ruault,, ${ }^{1,6}$ Raphaele Seror (i) ${ }^{4,5}$
}

To cite: Nguyen $Y$, Salliot C, Gelot $\mathrm{A}$, et al. Passive smoking in childhood and adulthood and risk of rheumatoid arthritis in women: results from the French E3N cohort study. RMD Open 2022;8:e001980. doi:10.1136/ rmdopen-2021-001980

- Additional supplemental material is published online only. To view, please visit the journal online (http://dx.doi.org/10. 1136/rmdopen-2021-001980).

M-CB-R and RS contributed equally.

Received 29 September 2021 Accepted 30 January 2022
Check for updates

C) Author(s) (or their employer(s)) 2022. Re-use permitted under CC BY-NC. No commercial re-use. See rights and permissions. Published by BMJ.

For numbered affiliations see end of article.

Correspondence to Dr Marie-Christine BoutronRuault;

marie-christine.boutron@ gustaveroussy.fr

\section{ABSTRACT}

Objective The association between passive smoking exposure in childhood or in adulthood, and the risk of rheumatoid arthritis (RA) has been incompletely investigated. We aimed to assess the relationship between exposure to passive smoking and the risk of incident RA in a French prospective cohort of healthy women.

Methods The E3N Study (Etude Epidémiologique auprès des femmes de la Mutuelle générale de l'Education Nationale) is a French prospective cohort of women included in 1990. Exposures to passive smoking were assessed using self-reported questionnaires. RA cases were self-reported and subsequently validated. Cox proportional hazards regression models adjusted for age and for potential confounders were used to estimate HRs and $95 \%$ Cls for incident RA.

Results Among 79806 women, 698 incident cases of RA were identified; 10810 (13.5\%) women were exposed to passive smoking in childhood, and 42807 (53.6\%) in adulthood. Median age at inclusion was 47.8 years. Passive smoking in childhood and in adulthood was associated with RA risk in all models (HRs $(95 \% \mathrm{Cls}) 1.24$ (1.01 to 1.51 ) and 1.19 (1.02 to 1.40 ), respectively). The absolute risk of RA among never smokers with exposure to passive smoking in childhood and/or adulthood (47.6/100 000 person-years) was close to the risk of ever smokers with no passive smoking exposure (47.2/100 000 personyears), while it was highest in ever smokers also exposed to passive smoking (53.7/100 000 person-years). Conclusion Exposure to passive smoking in childhood and/or adulthood increases the risk of RA by the same order than active smoking. Such exposure should be suppressed, especially in individuals at risk of RA.

\section{INTRODUCTION}

Rheumatoid arthritis (RA) is an inflammatory rheumatic disease of complex pathogenesis. Genetic and environmental factors are thought to interact to trigger autoimmunity leading to the disease. ${ }^{1}$ Personal active smoking has been the most reproducibly reported risk factor for RA, particularly

\section{Key messages}

What is already known about this subject?

- To date, only a few studies assessed the association between passive smoking and the risk of rheumatoid arthritis (RA), and results are conflicting.

What does this study add?

- In this prospective cohort of almost 80000 women, passive smoking exposure during childhood and/or adulthood was associated with an increased risk of RA, especially in never smokers. Passive smoking in childhood is particularly associated with the risk of RA, which may occur earlier than in women never exposed to smoking.

How might this impact on clinical practice or further developments?

- Our results support the hypothesis that passive smoking is associated with the risk of RA. Exposure to passive smoking, especially during childhood, should be limited as much as possible, especially in individuals at high risk of RA.

in patients carrying the HLA-DRB1-shared epitope (SE) alleles. ${ }^{2-5}$

While secondhand smoking could increase disease activity in women with $\mathrm{RA}^{6}{ }^{6}$ only a few studies assessed the association between passive smoking (PS) and the risk of RA, and results are conflicting. In adulthood, PS exposure at work or at home was not associated with RA in two case-control studies and one cohort study. ${ }^{7-9}$ In a previous work in the E3N cohort of French women, we identified for the first time that, compared with never smokers not exposed to PS in childhood, ever-smoking women exposed to PS in childhood had an increased risk of RA. ${ }^{10}$ In this preliminary work, we could not identify PS as a risk factor independent of active smoking, possibly because of underpowered analysis. 
Indeed, at the time of the study, only part of RA cases were identified, that is, only 371 incident RA cases. ${ }^{10}$

Thus, now that more RA cases have been identified, ${ }^{11}$ the objectives of this prospective study were to investigate the relationship between PS in childhood and/or adulthood, and the risk of incident RA in a large prospective cohort of healthy French women.

\section{MATERIAL AND METHODS \\ Study population}

The French E3N Study (Etude Epidémiologique auprès des femmes de la Mutuelle générale de l'Education Nationale) is a prospective cohort, initially conceived to study environmental risk factors for cancers and chronic diseases. It includes 98995 healthy French women, primarily teachers, since 1990 covered by a national health insurance. Follow-up is still ongoing. ${ }^{12}$ They were sent every 2-3 years questionnaires (Q1-Q12) with questions on their health, lifestyle and newly diagnosed diseases. The average response rate per questionnaire is $83 \%$, and less than $3 \%$ of the participants were lost to follow-up since 1990. Signed consent was obtained from all participants.

\section{RA ascertainment}

Identification of RA cases has been previously described. ${ }^{11}$ Briefly, participants who self-reported having RA in the follow-up questionnaires were sent a validation questionnaire adapted from Guillemin $e t a l^{13}$ in 2017. Women were considered as cases if they confirmed having RA in this validation questionnaire and if any of the following criteria were fulfilled: (1) RA was confirmed by a physician, (2) they self-reported taking any disease-modifying antirheumatic drugs (DMARDs) considered specific of RA, (3) they self-reported having positive auto-antibodies (rheumatoid factors and/or anti-citrullinated protein antibodies), (4) at least four of the seven 1987-American College of Rheumatology (ACR) criteria were met. Sensitivity and specificity of this algorithm were $93.8 \%$ and $82.6 \%$, respectively. For women who did not answer the specific validation questionnaire, we used the medication reimbursement database and women were considered as cases if they had had reimbursements of any DMARDs considered to be specific of RA. Sensitivity and specificity of this method were $70.5 \%$ and $87.3 \%$, respectively.

For the present study, only incident cases, diagnosed after 1990, were considered and we excluded women who did not complete any of the three questionnaires (Q9, Q10 and Q11) collecting self-reported diagnosis of RA, prevalent RA cases occurring before baseline and RA cases with unavailable date of diagnosis.

\section{Variables of interest}

At inclusion, women had to answer the following question: 'When you were a child, did you stay in a smoky room?'. Answer modalities were 'never', 'do not remember', 'rarely', 'occasionally (a few hours a week)', 'a few hours a day' or 'several hours a day'. Women were considered exposed to PS in childhood if the answers were 'a few hours a day' or 'several hours a day'.

PS exposure in adulthood was assessed at inclusion by asking the women to sum their time spent at home or outside the home during the day in a room while someone was smoking. This time was expressed in hours: ' 0 ', ' $<1$ hour' or the number of hours. They were considered exposed if they were exposed at least 1 hour a day.

Education (<high school; up to two-level university; three/four-level university) was self-reported and collected in the first questionnaire. Weight and height were also self-reported in the first questionnaire and used to calculate body mass index (BMI; $<18.5 \mathrm{~kg} / \mathrm{m}^{2}, 18.5-25$ $\left.\mathrm{kg} / \mathrm{m}^{2}, 25-30 \mathrm{~kg} / \mathrm{m}^{2}, \geq 30 \mathrm{~kg} / \mathrm{m}^{2}\right)$. Weight has been additionally measured in approximatively 10 000women who provided a blood sample at a collection centre, and correlation between self-report and measured BMI was excellent. Personal smoking status (non-smoker, former smoker and current smoker) at inclusion was also available.

\section{Statistical analyses}

Follow-up began on the date the first questionnaire was returned in 1990 (baseline), and women contributed person-time until the date of RA diagnosis, the last completed questionnaire until the 2017 questionnaire (Q11), death or loss to follow-up, whichever occurred first.

In descriptive analyses, results were expressed as count (\%) for categorical variables and median (IQR) for continuous variables.

To estimate the risk of RA associated with PS (HR and their 95\% CIs), we used Cox multivariable regression models with age as the timescale (model 1), and adjusted on baseline smoking status (never, current or former smoker), the other types of PS, educational level ( $<$ high school, up to two-level university, three/four-level university) and baseline BMI $\left(<18.5 \mathrm{~kg} / \mathrm{m}^{2}, 18.5-25 \mathrm{~kg} /\right.$ $\mathrm{m}^{2}, 25-30 \mathrm{~kg} / \mathrm{m}^{2}, \geq 30 \mathrm{~kg} / \mathrm{m}^{2}$ ) (model 2$)$. Analyses were stratified on smoking status (ever or never smokers). Potential interactions between active smoking status and PS were investigated. In addition, we built up a model that considered both exposure to PS in childhood and/ or adulthood and personal smoking (ever and never smokers). This model was used to calculate absolute risks of RA associated with combinations of smoking status and PS in childhood and/or adulthood.

We also performed a sensitivity analysis on seropositive incident RA cases only, by excluding seronegative cases, or with unknown seropositivity status. Models 1 and 2 were fitted on this population.

Finally, we compared mean ages at RA onset according to PS exposure in childhood and/or in adulthood and according to personal smoking (ever or never smokers) with analyses of variance.

All statistical analyses were carried out using SAS software, V.9.3 (SAS Institute). All p values were two tailed and considered significant if $\mathrm{p}<0.05$. 


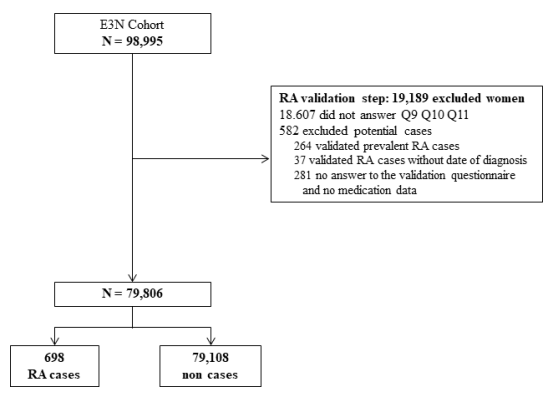

Figure 1 Flow chart of the study among women in the E3N cohort. E3N, Etude Epidémiologique auprès des femmes de la Mutuelle générale de l'Education Nationale; RA, rheumatoid arthritis.

\section{Patient and public involvement}

Patients and the public were not directly involved in the design or completion of this study.

\section{RESULTS}

\section{Characteristics of the study population}

Among the 98995 women of the cohort, the study population included 79806 women during a total of 1897583 person-years of follow-up, including 698 incident RA cases (figure 1). Median (IQR) follow-up was 24.47 (24.33-24.54) years, and median age at cohort entry was 47.9 (43.5-53.5) years. Incident RA cases were diagnosed after a median of 14.9 (8.6-19.2) years after baseline and median age at RA diagnosis was $63.4(57.7-70.3)$ years. Antibody status was known for $230(33.0 \%)$ incident cases and $210(91 \%)$ of them were seropositive.
Characteristics of the overall study population according to PS in childhood and in adulthood are presented in table 1 . In the whole study population, $10810(13.5 \%)$ women were exposed to PS in childhood, $42807(53.6 \%)$ to PS in adulthood, $6581(8.25 \%)$ were exposed to both and $47036(58.9 \%)$ were exposed to either. Regarding active smoking, 36636 (45.91\%) had ever smoked (14.19\% current and $31.71 \%$ former smokers). Compared with never smokers, current, former and ever smokers had similar increased risk of RA: HRs (95\% CIs) 1.30 (1.04 to 1.63 ); 1.21 (1.13 to 1.42 ); 1.23 (1.06 to 1.43 ), respectively.

\section{PS in childhood and risk of RA}

In the whole population, PS in childhood was positively associated with the risk of RA in all models, including adjustment on PS in adulthood (HR 1.24; 95\% CI 1.01 to 1.51 in model 2) (table 2). When stratifying on active smoking status, PS in childhood was associated with RA only in never-smoking women (HR 1.40; $95 \%$ CI 1.06 to 1.86). However, the interaction term was not statistically significant $(\mathrm{p}=0.28)$. In the whole population, compared with never smokers with no passive smoking in childhood, RA risk of never smokers exposed to PS in childhood was increased (HR 1.38; 95\% CI 1.04 to 1.83), and of the same magnitude as the risk of ever smokers with exposure to PS in childhood (HR 1.37; 95\% CI 1.03 to 1.82).

When restricting our analyses to the 210 seropositive incident cases, PS in childhood was still associated with the risk of seropositive RA (HR 1.55; 95\% CI 1.10 to

Table 1 Baseline characteristics of the study population of the E3N cohort $(\mathrm{N}=79806)$

\begin{tabular}{|c|c|c|c|c|c|}
\hline & \multirow[b]{2}{*}{ All ( $N=79806)$} & \multicolumn{2}{|c|}{ Passive smoking in childhood } & \multicolumn{2}{|c|}{ Passive smoking in adulthood } \\
\hline & & No $(\mathrm{N}=68996)$ & Yes $(\mathrm{N}=10810)$ & No $(\mathrm{N}=36999)$ & Yes $(\mathrm{N}=42807)$ \\
\hline Age at baseline (years) & $\begin{array}{l}47.8(43.6- \\
53.5)\end{array}$ & $\begin{array}{l}47.9(43.5- \\
53.6)\end{array}$ & $47.4(43.2-53.0)$ & $\begin{array}{l}49.3(44.1- \\
55.3)\end{array}$ & $\begin{array}{l}46.9 \text { (43.1- } \\
52.0)\end{array}$ \\
\hline \multicolumn{6}{|l|}{ Body mass index $\left(\mathrm{kg} / \mathrm{m}^{2}\right)$} \\
\hline$<18.5 \mathrm{~kg} / \mathrm{m}^{2}$ & $1738(2.2)$ & $1523(2.2)$ & $215(2.0)$ & $745(2.0)$ & $993(2.3)$ \\
\hline $18.5-25 \mathrm{~kg} / \mathrm{m}^{2}$ & $65255(81.8)$ & $56506(81.9)$ & 8749 (80.9) & $30332(82.0)$ & $34923(81.6)$ \\
\hline $25-30 \mathrm{~kg} / \mathrm{m}^{2}$ & $10737(13.5)$ & $9203(13.3)$ & $1534(14.2)$ & 5047 (13.6) & 5690 (13.3) \\
\hline$\geq 30 \mathrm{~kg} / \mathrm{m}^{2}$ & $2076(2.5)$ & $1764(2.6)$ & $312(2.9)$ & $875(2.4)$ & $1201(2.8)$ \\
\hline \multicolumn{6}{|l|}{ Educational level } \\
\hline$<$ High school & $12025(15.1)$ & $10195(14.7)$ & $1830(16.9)$ & $5952(16.1)$ & $6073(14.1)$ \\
\hline Up to 2-level university & $40306(50.5)$ & $34743(50.4)$ & $5563(51.5)$ & $20549(55.5)$ & $19757(46.2)$ \\
\hline 3/4-level university & $27475(34.4)$ & $24058(34.9)$ & 3417 (31.6) & $10498(28.4)$ & $16977(39.7)$ \\
\hline \multicolumn{6}{|l|}{ Smoking status } \\
\hline Current smoker & $11328(14.2)$ & $9734(14.1)$ & $1594(14.7)$ & $2269(6.1)$ & 9059 (21.2) \\
\hline Non-smoker & $43170(54.1)$ & $37917(55.0)$ & $5253(48.6)$ & $23322(63.1)$ & $19848(46.4)$ \\
\hline Former smoker & $25308(31.7)$ & $21345(30.9)$ & $3963(36.7)$ & $11408(30.8)$ & 13900 (32.4) \\
\hline Diabetes mellitus & $575(0.7)$ & $487(0.7)$ & $88(0.8)$ & $286(0.8)$ & $289(0.7)$ \\
\hline
\end{tabular}

Baseline was the date of the first questionnaire (1990). Results are expressed as N (\%) for categorical variables and median (IQR) for continuous variables. No missing data.

E3N, Etude Epidémiologique auprès des femmes de la Mutuelle générale de l'Education Nationale. 
Table 2 HRs (95\% Cls) for incident rheumatoid arthritis according to passive smoking in childhood, overall and after stratified by ever-smoking status among women in the E3N cohort ( $N=79806)$

\begin{tabular}{|c|c|c|c|}
\hline & $\begin{array}{l}\text { Cases, no/person- } \\
\text { years, no }\end{array}$ & $\begin{array}{l}\text { Model } 1 \\
\text { HR (95\% CI) }\end{array}$ & $\begin{array}{l}\text { Model } 2 \\
\text { HR }(95 \% \mathrm{Cl})\end{array}$ \\
\hline \multicolumn{4}{|l|}{ All population ( $\mathrm{N}=79806)$} \\
\hline \multicolumn{4}{|l|}{ Passive smoking in childhood } \\
\hline No & $584 / 1640298$ & Reference & Reference \\
\hline Yes & $114 / 257284$ & 1.26 (1.03 to 1.54$)$ & 1.24 (1.01 to 1.51$)$ \\
\hline$P$ value & & 0.023 & 0.037 \\
\hline \multicolumn{4}{|l|}{ Never smokers $(\mathrm{N}=43170)$} \\
\hline \multicolumn{4}{|l|}{ Passive smoking in childhood } \\
\hline No & 293/900764 & Reference & Reference \\
\hline Yes & $57 / 124998$ & $1.42(1.07$ to 1.88$)$ & $1.40(1.06$ to 1.86$)$ \\
\hline$P$ value & & 0.016 & 0.019 \\
\hline \multicolumn{4}{|l|}{ Ever smokers ( $\mathrm{N}=36636)$} \\
\hline \multicolumn{4}{|l|}{ Passive smoking in childhood } \\
\hline No & $291 / 739535$ & Reference & Reference \\
\hline Yes & $57 / 132286$ & 1.11 (0.83 to 1.47$)$ & $1.10(0.83$ to 1.46$)$ \\
\hline$P$ value & & 0.48 & 0.50 \\
\hline \multicolumn{4}{|l|}{ All population $(\mathrm{N}=79806)$} \\
\hline Never smoker, no passive smoking in childhood & 293/900764 & Reference & Reference \\
\hline Never smoker, passive smoking in childhood & $57 / 124998$ & 1.41 (1.06 to 1.88$)$ & 1.38 (1.04 to 1.83$)$ \\
\hline Ever smoker, no passive smoking in childhood & $291 / 739535$ & 1.27 (1.08 to 1.50$)$ & $1.26(1.07$ to 1.49$)$ \\
\hline Ever smoker, passive smoking in childhood & $57 / 132286$ & 1.41 (1.06 to 1.87$)$ & $1.37(1.03$ to 1.82$)$ \\
\hline
\end{tabular}

Model 1: adjusted for age (as the timescale).

Model 2: adjusted for age (as the timescale), active smoking status (current smoker, non-smoker, former smoker, except for stratified analyses and combined analysis), passive smoking in adulthood, body mass index $\left(\mathrm{kg} / \mathrm{m}^{2}\right)\left(<18.5 \mathrm{~kg} / \mathrm{m}^{2}, 18.5-25 \mathrm{~kg} / \mathrm{m}^{2}, 25-30 \mathrm{~kg} / \mathrm{m}^{2}\right.$, $\geq 30 \mathrm{~kg} / \mathrm{m}^{2}$ ), and educational level (<high school, up to two-level university, three/four-level university).

$\mathrm{P}$ for interaction between smoking status and passive smoking during childhood $=0.28$.

E3N, Etude Epidémiologique auprès des femmes de la Mutuelle générale de l'Education Nationale.

2.18 in model 2), especially in never smokers (HR 1.67; $95 \%$ CI 1.03 to 2.71 in model 2), but not in ever smokers (table 3 ).

\section{PS in adulthood and risk of RA}

PS in adulthood was also associated with the risk of RA in all models, including adjustment on PS in childhood (HR 1.19; 95\% CI 1.02 to 1.40 in model 2) (table 4).

There was also no interaction between PS in adulthood and smoking. In analyses stratified on active smoking status, PS in adulthood was associated with an increased RA risk only in never-smoking women (HR 1.27; 95\% CI 1.02 to 1.57$)$. In the whole population, in model 2, compared with never smokers with no PS in adulthood, RA risk of never smokers exposed to PS in adulthood was increased (HR 1.24; 95\% CI 1.00 to 1.53 ) and was of the same magnitude as the risk of ever smokers without exposure to PS in adulthood (HR 1.26; 95\% CI 1.00 to 1.59). The risk of RA was the highest if women were both ever smokers and exposed to PS in adulthood (HR 1.46; $95 \%$ CI 1.20 to 1.79$)$.
In the sensitivity analyses, the association between PS in adulthood and incident seropositive RA was no longer found (online supplemental table 1).

\section{PS in childhood and/or adulthood and risk of RA}

In the whole population, compared with women never exposed to smoking-actively or passively (childhood and/or adulthood) -, women exposed to PS (in childhood and/or adulthood), whatever the active smoking status, were at increased risk of RA (figure 2). The absolute risk of RA was lowest in those never exposed to smoking-actively or passively-(35.8/100 000 personyears), while it was highest in ever smokers also exposed to PS (53.7/100 000 person-years). The absolute risk of RA in never-smoking women exposed to PS (47.6/100 000 person-years) was very close to the risk of ever smokers not exposed to PS (47.2/100 000 person-years).

\section{PS and age at RA onset}

Age at RA onset was highest among women never exposed to smoking-actively or passively (childhood and/or adulthood) (66.55 \pm 9.30 years), while it was lowest among 
Table 3 HRs (95\% Cls) for incident seropositive rheumatoid arthritis (RA) according to passive smoking in childhood, overall and after stratified by ever-smoking status among women in the E3N cohort ( $\mathrm{N}=79318)$

\begin{tabular}{|c|c|c|c|}
\hline & $\begin{array}{l}\text { Seropositive RA cases, no/ } \\
\text { person-years, no }\end{array}$ & $\begin{array}{l}\text { Model } 1 \\
\text { HR }(95 \% \mathrm{Cl})\end{array}$ & $\begin{array}{l}\text { Model } 2 \\
\text { HR }(95 \% \mathrm{Cl})\end{array}$ \\
\hline All population $(\mathrm{N}=79318)$ & $\mathrm{N}=210$ & & \\
\hline \multicolumn{4}{|l|}{ Passive smoking in childhood } \\
\hline No & $169 / 1634324$ & Reference & Reference \\
\hline Yes & $41 / 2562263$ & 1.55 (1.10 to 2.18$)$ & 1.55 (1.10 to 2.18$)$ \\
\hline$P$ value & & 0.012 & 0.012 \\
\hline Never smokers $(\mathrm{N}=42927)$ & $\mathrm{N}=107$ & & \\
\hline \multicolumn{4}{|l|}{ Passive smoking in adulthood } \\
\hline No & $87 / 897762$ & Reference & Reference \\
\hline Yes & $20 / 124430$ & 1.66 (1.02 to 2.70$)$ & $1.67(1.03$ to 2.71$)$ \\
\hline$P$ value & & 0.041 & 0.039 \\
\hline Ever smokers ( $\mathrm{N}=36391)$ & $\mathrm{N}=103$ & & \\
\hline \multicolumn{4}{|l|}{ Passive smoking in adulthood } \\
\hline No & $82 / 736562$ & Reference & Reference \\
\hline Yes & $21 / 131834$ & 1.44 (0.89 to 2.32$)$ & $1.44(0.89$ to 2.32$)$ \\
\hline$P$ value & & 0.14 & 0.13 \\
\hline All population $(\mathrm{N}=79318)$ & $\mathrm{N}=210$ & & \\
\hline Never smoker, no passive smoking in childhood & $87 / 897762$ & Reference & Reference \\
\hline Never smoker, passive smoking in childhood & $20 / 124430$ & 1.66 (1.02 to 2.70$)$ & 1.68 (1.03 to 2.73$)$ \\
\hline Ever smoker, no passive smoking in childhood & $82 / 736562$ & $1.15(0.85$ to 1.56$)$ & $1.15(0.85$ to 1.57$)$ \\
\hline Ever smoker, passive smoking in childhood & $21 / 131834$ & 1.66 (1.03 to 2.67$)$ & 1.66 (1.03 to 2.69$)$ \\
\hline
\end{tabular}

Model 1: adjusted for age (as the timescale).

Model 2: adjusted for age (as the timescale), active smoking status (current smoker, non-smoker, former smoker, except for stratified analyses and combined analysis), passive smoking in adulthood, body mass index $\left(\mathrm{kg} / \mathrm{m}^{2}\right)\left(<18.5 \mathrm{~kg} / \mathrm{m}^{2}, 18.5-25 \mathrm{~kg} / \mathrm{m}^{2}, 25-30 \mathrm{~kg} / \mathrm{m}^{2}, \geq 30 \mathrm{~kg} / \mathrm{m}^{2}\right)$, and educational level (<high school, up to two-level university, three/four-level university).

E3N, Etude Epidémiologique auprès des femmes de la Mutuelle générale de l'Education Nationale.

ever-smoking women exposed to PS in childhood whatever PS exposure in adulthood exposure $(60.7 \pm 9.19$ years if also exposed during adulthood, and $60.3 \pm 8.83$ if not) (table 5). Age at RA onset was in between, and similar among never smokers exposed to PS and ever smokers not exposed to PS.

\section{DISCUSSION}

In this large, population-based prospective cohort study of French women, we reported that PS exposure during childhood and/or adulthood was associated with an increased risk of RA, especially in never-active smokers. This risk was similar to the one of ever-active smokers without exposure to PS especially during adulthood. Interestingly, the size effects related to PS exposure in childhood and in adulthood (HRs 1.26 and 1.24, respectively) were similar to the one of patients who smoked between 1 and 10 pack-years according to a meta-analysis (HR 1.26; 95\% CI 1.14 to 1.39 compared with never smokers). ${ }^{14}$

In addition, we found an even stronger association between PS in childhood and seropositive RA, especially among never smokers, and that RA exposed to PS in childhood was diagnosed earlier than RA never exposed to smoking. Among ever smokers, we failed to find any association between PS exposure in childhood or in adulthood with the risk of RA. Untangling the proper effect of secondhand smoke from primary smoke exposure would require larger populations with different levels of primary smoke exposure.

Our findings reinforce existing hypotheses and understanding of RA pathogenesis, and add to the mucosal paradigm of RA pathogenesis. It is well established that smoking favours citrullination and, in genetically predisposed people, immunisation to citrulline can occur years before the first symptoms of the disease. ${ }^{35}$ The fact that exposure to smoking at the very beginning of life could be associated with RA suggests that autoimmunity could be triggered even earlier and many years before the onset of the symptoms.

Previous attempts have been made to assess the association between PS exposure and RA. In the Nurses' Health Study I prospective cohort, there was no association between PS exposure although PS exposure was assessed by the number of years lived with a smoker. ${ }^{7}$ However, long exposure to PS ( $\geq 30$ years of exposure) was marginally associated with incident RA both in ever and never smokers, suggesting a potential link. More recently, the 
Table 4 HRs (95\% Cls) for incident rheumatoid arthritis according to passive smoking in adulthood, overall and after stratified by ever-smoking status among women in the E3N cohort ( $\mathrm{N}=79806)$

\begin{tabular}{|c|c|c|c|}
\hline & $\begin{array}{l}\text { Cases, no/person-years, } \\
\text { no }\end{array}$ & $\begin{array}{l}\text { Model } 1 \\
\text { HR }(95 \% \mathrm{Cl})\end{array}$ & $\begin{array}{l}\text { Model } 2 \\
\text { HR }(95 \% \mathrm{Cl})\end{array}$ \\
\hline \multicolumn{4}{|l|}{ All population $(\mathrm{N}=79806)$} \\
\hline \multicolumn{4}{|l|}{ Passive smoking in adulthood } \\
\hline No & $297 / 878178$ & Reference & Reference \\
\hline Yes & $401 / 1019405$ & $1.24(1.07$ to 1.44$)$ & $1.19(1.02$ to 1.40$)$ \\
\hline$P$ value & & 0.005 & 0.025 \\
\hline \multicolumn{4}{|l|}{ Never smokers $(\mathrm{N}=43170)$} \\
\hline \multicolumn{4}{|l|}{ Passive smoking in adulthood } \\
\hline No & $175 / 553281$ & Reference & Reference \\
\hline Yes & $175 / 472481$ & $1.26(1.02$ to 1.56$)$ & $1.27(1.02$ to 1.57$)$ \\
\hline$P$ value & & 0.032 & 0.029 \\
\hline \multicolumn{4}{|l|}{ Ever smokers $(\mathrm{N}=36636)$} \\
\hline \multicolumn{4}{|l|}{ Passive smoking in adulthood } \\
\hline No & $122 / 324897$ & Reference & Reference \\
\hline Yes & $226 / 546923$ & 1.15 (0.92 to 1.43$)$ & $1.16(0.93$ to 1.44$)$ \\
\hline$P$ value & & 0.22 & 0.20 \\
\hline \multicolumn{4}{|l|}{ All population $(\mathrm{N}=79806)$} \\
\hline Never smoker, no passive smoking in adulthood & $175 / 553281$ & Reference & Reference \\
\hline Never smoker, passive smoking in adulthood & $175 / 472481$ & $1.25(1.01$ to 1.54$)$ & $1.24(1.00$ to 1.53$)$ \\
\hline Ever smoker, no passive smoking in adulthood & $122 / 324897$ & $1.24(0.99$ to 1.57$)$ & $1.26(1.00$ to 1.59$)$ \\
\hline Ever smoker, passive smoking in adulthood & $226 / 546923$ & $1.45(1.18$ to 1.76$)$ & $1.46(1.20$ to 1.79$)$ \\
\hline
\end{tabular}

Model 1: adjusted for age (as the timescale).

Model 2: adjusted for age (as the timescale), active smoking status (current smoker, non-smoker, former smoker, except for stratified and combined analyses), passive smoking in childhood, body mass index $\left(\mathrm{kg} / \mathrm{m}^{2}\right)\left(<18.5 \mathrm{~kg} / \mathrm{m}^{2}, 18.5-25 \mathrm{~kg} / \mathrm{m}^{2}, 25-30 \mathrm{~kg} / \mathrm{m}^{2}, \geq 30 \mathrm{~kg} / \mathrm{m}^{2}\right)$, and educational level (<high school, up to two-level university, three/four-level university).

$P$ for interaction between smoking status and passive smoking during adulthood $=0.40$.

E3N, Etude Epidémiologique auprès des femmes de la Mutuelle générale de l'Education Nationale.

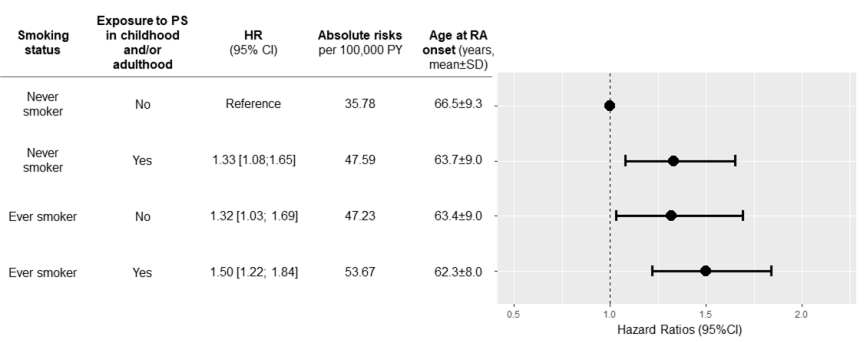

Figure 2 Risk of incident RA and age at RA onset according to smoking status and exposure to passive smoking (PS) during childhood and/or during adulthood among women in the E3N cohort. Results are expressed as HRs with bars representing $95 \% \mathrm{Cls}$. This model was adjusted on age (as the timescale), body mass index and educational level, and used to calculate absolute risks of RA associated with smoking status and exposure to PS in childhood and/or in adulthood. This model was used to calculate absolute risks of RA associated with combinations of active smoking status and PS in childhood and/or adulthood. E3N, Etude Epidémiologique auprès des femmes de la Mutuelle générale de l'Education Nationale; PY: personyears; RA, rheumatoid arthritis. association of life course PS and the risk of incident RA has been reported in the Nurses' Health Study II cohort. ${ }^{15}$ Childhood exposure measured by childhood parental smoking was associated with a $41 \%$ increased risk of seropositive RA after adjustment for potential confounders, and a $75 \%$ increased risk after further adjustment for adulthood active and passive smoking. The association was even stronger among ever smokers, while there was no association in never smokers. These results are consistent with ours, even though, we mainly observed an increased RA risk associated with PS exposure in childhood in never smokers. In a Swedish populationbased case-control study including 589 cases and 1769 controls, there was no association between exposure to PS (at home or at work) and the risk of RA. ${ }^{8}$ However, the authors did not separately consider PS exposure in childhood and in adulthood, and the retrospective design of the study might be prone to differential recall bias.

We acknowledge some limitations to our study. First, our cohort only studied women. However, incidence of RA being higher in women, our study population was appropriate to test our hypothesis. In addition, 
Table 5 Age at RA onset according to smoking status among women in the E3N cohort ( $N=79806)$

\begin{tabular}{|c|c|c|c|}
\hline Smoking status & RA, N & Age at RA, years & P value \\
\hline According to passive smoking in childhood & & & 0.0015 \\
\hline Never smoker, no passive smoking in childhood & 293 & $65.1(9.3)$ & \\
\hline Never smoker, passive smoking in childhood & 57 & $64.2(8.9)$ & \\
\hline Ever smoker, no passive smoking in childhood & 291 & $63.0(8.6)$ & \\
\hline Ever smoker, passive smoking in childhood & 57 & $60.6(9.0)$ & \\
\hline According to passive smoking in adulthood & & & 0.0002 \\
\hline Never smoker, no passive smoking in adulthood & 175 & $66.3(9.0)$ & \\
\hline Never smoker, passive smoking in adulthood & 175 & $63.5(9.2)$ & \\
\hline Ever smoker, no passive smoking in adulthood & 122 & $63.0(10.0)$ & \\
\hline Ever smoker, passive smoking in adulthood & 226 & $62.4(7.9)$ & \\
\hline According to passive smoking in childhood and/or adulthood & & & 0.001 \\
\hline Never smoker, no passive smoking in childhood, no passive smoking in adulthood & 149 & $66.5(9.3)$ & \\
\hline Never smoker, no passive smoking in childhood, passive smoking in adulthood & 144 & $63.5(9.0)$ & \\
\hline Never smoker, passive smoking in childhood, no passive smoking in adulthood & 26 & $64.6(7.3)$ & \\
\hline Never smoker, passive smoking in childhood, passive smoking in adulthood & 31 & $63.7(10.2)$ & \\
\hline Ever smoker, no passive smoking in childhood, no passive smoking in adulthood & 107 & $63.4(10.1)$ & \\
\hline Ever smoker, no passive smoking in childhood, passive smoking in adulthood & 184 & $62.8(7.5)$ & \\
\hline Ever smoker, passive smoking in childhood, no passive smoking in adulthood & 15 & $60.3(8.8)$ & \\
\hline Ever smoker, passive smoking in childhood, passive smoking in adulthood & 42 & $60.7(9.2)$ & \\
\hline According to passive smoking in childhood and/or adulthood & & & $<0.001$ \\
\hline Never smoker, no passive smoking in childhood and/or in adulthood & 149 & $66.5(9.3)$ & \\
\hline Never smoker, passive smoking in childhood and/or in adulthood & 201 & $63.7(9.0)$ & \\
\hline Ever smoker, no passive smoking in childhood and/or passive smoking in adulthood & 107 & $63.4(9.0)$ & \\
\hline Ever smoker, passive smoking in childhood and/or passive smoking in adulthood & 31 & $62.3(8.0)$ & \\
\hline
\end{tabular}

Results are expressed as $\mathrm{N}$ for categorical variables and mean (SD) for continuous variables.

E3N, Etude Epidémiologique auprès des femmes de la Mutuelle générale de l'Education Nationale; RA, rheumatoid arthritis.

identification of RA cases was based on self-reported data. However, the accuracy of our case identification was improved by our algorithms. Antibody status was known in only $230(33 \%)$ RA cases, and 210 of them $(91 \%)$ were seropositive, which further validates our algorithm for the diagnosis of RA. The low rate of antibody status is due to the self-reported design of the questionnaire, and the difficulties for patients to report their serological status. However, even with a reduced power, we still found an even stronger association between PS in childhood and seropositive RA, reinforcing our hypothesis. We acknowledge that exposure to PS was assessed only at a single time at baseline and we did not have quantitative data on cumulative personal active smoking and pack-years. In addition, exposure to PS in childhood was retrospectively collected, which might be prone to recall bias. However, because this question was asked years before the onset of RA, this bias should not be differential. Although we adjusted our analyses on several potential confounders, we did not adjust for other factors such as diet, lifestyle or air pollution, as data were either not available or available only in a fraction of the cohort. However, our study was mostly focused on investigating associations with childhood PS, which was unlikely to be strongly confounded by adult dietary or lifestyle behaviours. However, this could have potentially had an impact on our assessment of associations with adult PS. We were not able to investigate a potential gene-environment interaction, lacking data on the HLA-DRB1-SE and on family history. Finally, we could not perform analyses on RA severity, including radiological changes and clinical severity, and because we excluded prevalent cases occurring before baseline, our results might not apply to early life RA occurring before the inclusion, leading to a higher median age of RA onset.

Nevertheless, the strengths of our study include the large cohort size and the high number of RA, during a long follow-up period. In addition, we stratified our analyses on personal smoking exposure and were able to study the effect of PS on never-smoking women.

To conclude, PS during childhood and/or adulthood was associated with an increased risk of RA, especially among never-smoking women. Such exposure should be limited as much as possible to prevent the onset of the disease. Even if our study was not designed to investigate this point, this message could especially apply to individuals at risk of RA, for example, relatives of patients with RA. 
Author affiliations

${ }^{1}$ Centre for Research in Epidemiology and Population Health (CESP), Institut pour la Santé et la Recherche Médicale (INSERM) U1018, Université Paris-Saclay, Villejuif, France

2Department of Internal MedicineClichy, France, AP-HP.Nord, Hôpital Beaujon, Université de Paris, Clichy, France

${ }^{3}$ Department of Rheumatology, Centre Hospitalier Régional d'Orléans, Orléans, France

${ }^{4}$ Department of Rheumatology and National Reference Center for Rare Systemic Autoimmune Diseases, AP-HP, Hôpital Bicêtre, Université Paris-Saclay, Le KremlinBicêtre, France

${ }^{5}$ Centre for Immunology of Viral Infections and Autoimmune diseases, INSERM UMR1184, Université Paris-Saclay, Le Kremlin-Bicêtre, France

${ }^{6}$ Gustave Roussy Institute, Villejuif, France

Acknowledgements The authors acknowledge all participants of the E3N Study for their continued participation. The authors would like to thank Pascale GerbouinRerolle and Roselyn Rima Gomes for their help on data management.

Contributors All authors contributed to the manuscript. YN, CS, XM, M-CB-R and RS were responsible for conception and design. YN, M-CB-R and RS were responsible for data collection and analysis. All authors were responsible for the interpretation of data. YN wrote the first version of the manuscript. All authors critically revised and approved the final version of the manuscript. All authors agreed to be accountable for all aspects of the work and attest to the accuracy and integrity of the work.

Funding The present work was performed using data from the Inserm E3N cohort and support from the MGEN, Gustave Roussy and the Ligue contre le Cancer for setting up and maintaining the cohort. The cohort was supported by a state grant ANR-10-COHO-0006 from the Agence Nationale de la Recherche within the Investissement d'Avenir programme. This study was conducted thanks to a research grant from FOREUM Foundation for Research in Rheumatology. In addition, the validation study was conducted with the financial support from the Société Française de Rhumatologie.

Competing interests None declared.

Patient consent for publication Not required.

Ethics approval This study involves human participants and approval was obtained from the French National Commission for Data Protection and Individual Freedom (327346-V14) and the French Advisory Committee on Information Processing in Material Research in the Field of Health (13.794). Participants gave informed consent to participate in the study before taking part.

Provenance and peer review Not commissioned; externally peer reviewed. Data availability statement Data are available upon reasonable request.

Open access This is an open access article distributed in accordance with the Creative Commons Attribution Non Commercial (CC BY-NC 4.0) license, which permits others to distribute, remix, adapt, build upon this work non-commercially, and license their derivative works on different terms, provided the original work is properly cited, appropriate credit is given, any changes made indicated, and the use is non-commercial. See: http://creativecommons.org/licenses/by-nc/4.0/.

ORCID iDs

Yann Nguyen http://orcid.org/0000-0002-0866-3824
Xavier Mariette http://orcid.org/0000-0002-4244-5417

Raphaele Seror http://orcid.org/0000-0002-5523-1856

\section{REFERENCES}

1 Klareskog L, Padyukov L, Rönnelid J, et al. Genes, environment and immunity in the development of rheumatoid arthritis. Curr Opin Immunol 2006;18:650-5.

2 Karlson EW, Chang S-C, Cui J, et al. Gene-Environment interaction between HLA-DRB1 shared epitope and heavy cigarette smoking in predicting incident rheumatoid arthritis. Ann Rheum Dis 2010;69:54-60.

3 Linn-Rasker SP, van der Helm-van Mil AHM, van Gaalen FA, et al. Smoking is a risk factor for anti-CCP antibodies only in rheumatoid arthritis patients who carry HLA-DRB1 shared epitope alleles. Ann Rheum Dis 2006;65:366-71.

4 Willemze A, van der Woude D, Ghidey W, et al. The interaction between HLA shared epitope alleles and smoking and its contribution to autoimmunity against several citrullinated antigens. Arthritis Rheum 2011;63:1823-32.

5 Too CL, Yahya A, Murad S, et al. Smoking interacts with HLA-DRB1 shared epitope in the development of anti-citrullinated protein antibody-positive rheumatoid arthritis: results from the Malaysian epidemiological investigation of rheumatoid arthritis (MyEIRA). Arthritis Res Ther 2012:14:R89.

6 Hammam N, Gheita TA. Impact of secondhand smoking on disease activity in women with rheumatoid arthritis. Clin Rheumatol 2017;36:2415-20.

7 Costenbader KH, Feskanich D, Mandl LA, et al. Smoking intensity, duration, and cessation, and the risk of rheumatoid arthritis in women. Am J Med 2006;119:503.e1-503.e9.

8 Hedström AK, Stawiarz L, Klareskog L, et al. Smoking and susceptibility to rheumatoid arthritis in a Swedish population-based case-control study. Eur J Epidemiol 2018;33:415-23.

9 Kronzer VL, Crowson CS, Sparks JA, et al. Investigating asthma, allergic disease, passive smoke exposure, and risk of rheumatoid arthritis. Arthritis Rheumatol 2019;71:1217-24.

10 Seror R, Henry J, Gusto G, et al. Passive smoking in childhood increases the risk of developing rheumatoid arthritis. Rheumatology 2019;58:1154-62.

11 Nguyen Y, Salliot C, Gusto G, et al. Improving accuracy of selfreported diagnoses of rheumatoid arthritis in the French prospective E3N-EPIC cohort: a validation study. BMJ Open 2019;9:e033536.

12 Clavel-Chapelon F, van Liere MJ, Giubout C, et al. E3N, a French cohort study on cancer risk factors. E3N group. Etude Epidémiologique auprès de femmes de l'Education Nationale. Eur J Cancer Prev 1997:6:473-8.

13 Guillemin F, Saraux A, Fardellone P, et al. Detection of cases of inflammatory rheumatic disorders: performance of a telephone questionnaire designed for use by patient interviewers. Ann Rheum Dis 2003;62:957-63.

14 Di Giuseppe D, Discacciati A, Orsini N, et al. Cigarette smoking and risk of rheumatoid arthritis: a dose-response meta-analysis. Arthritis Res Ther 2014;16:R61.

15 Yoshida K, Wang J, Malspeis S, et al. Passive Smoking Throughout the Life Course and the Risk of Incident Rheumatoid Arthritis in Adulthood Among Women. Arthritis Rheumatol 2021;73:2219-28. 